\title{
VERIFICAÇÃO DA AUTOMEDICAÇÃO COM ANTIBIÓTICOS NO MUNICÍPIO DE SOURE-PA
}

\section{ARTIGO ORIGINAL}

MAUÉS, Karem Maria Gaia ${ }^{1}$

BIANCALANA, Fernanda Simas Correa ${ }^{2}$

BIANCALANA, Adriano ${ }^{3}$

GAIA, Sarah Nunes ${ }^{4}$

CAVALCANTE, Lívia Queiroz ${ }^{5}$

MAUÉS, Karem Maria Gaia. Et al. Verificação da automedicação com antibióticos no Município de Soure-PA. Revista Científica Multidisciplinar Núcleo do Conhecimento. Ano 05, Ed. 06, Vol. 12, pp. 136-148. Junho de 2020. ISSN: 24480959, Link de

acesso: https://www.nucleodoconhecimento.com.br/saude/automedicacao-comantibioticos

\section{RESUMO}

A automedicação é conceituada pelo uso de remédios sem prescrição, orientação ou auxílio de um profissional de saúde (médico), dentre os medicamentos observados

\footnotetext{
${ }^{1}$ Graduada pela Universidade Federal do Pará - UFPA (2020).

2 Doutora em Ciências Médicas pela Universidade Estadual de Campinas, Brasil (2011).

${ }^{3}$ Doutor em Biologia Celular e Estrutural pela Universidade Estadual de Campinas, Brasil (2009).

${ }^{4}$ Graduanda em Enfermagem na Universidade Estadual do Pará - UEPA.

${ }^{5}$ Graduanda pela Universidade Federal do Pará- UFPA.
} 
nessa prática estão os antibióticos. Eles são usados para matar bactérias ou eliminar o seu crescimento. Entretanto, o uso indevido deste fármaco, pode causar efeitos adversos, alergias, intoxicações e contribuir para o aumento da resistência bacteriana. Diante disso, o objetivo deste trabalho foi verificar a ocorrência da automedicação com antibióticos no município de Soure-PA. Para isso, foram selecionadas 10 pessoas de cada bairro da zona urbana e rural do município para aplicação do questionário, totalizando 120 entrevistas. Os dados revelaram que $57,5 \%$ das pessoas utilizavam antibiótico por conta própria, dos quais o motivo mais escolhido para justificar a prática foi o alívio imediato de algum sintoma e deste total, $33 \%$ eram do sexo feminino. 0 antibiótico amoxilina foi o mais relatado na pesquisa e os moradores da zona rural, consomem mais antibacterianos sem orientação médica. O estudo demonstra que a automedicação com antibióticos ocorre em Soure, o que é um risco para a população e um problema de saúde pública, tornando-se necessário o incentivo de práticas de educação em saúde que sensibilizem os indivíduos acerca dos danos provenientes da automedicação a fim de minimizar este hábito e contribuir com a melhoria da qualidade de vida dessas pessoas.

Palavras-chave: Antibacteriano, automedicação, risco biológico.

\section{INTRODUÇÃO}

Os medicamentos são essenciais para a melhoria do bem-estar da população, já que auxiliam no tratamento de doenças Arrais et al. (2005), seu uso pelos brasileiros é elevado Carvalho et al. (2003), devido acreditar que os medicamentos resolvem todos os sintomas, o que contribui para a prática da automedicação (NAVES et al., 2010).

A automedicação é conceituada pelo uso de remédios sem prescrição, orientação ou auxílio de um profissional especializado (médico) (BRASIL, 2011). No Brasil, pelo menos 35\% dos medicamentos utilizados é através de automedicação Aquino, (2008), o que é ocasionado pelo não cumprimento das regras de comercialização e fiscalização e de um sistema de saúde pouco estruturado (BORTOLON et al., 2008). 
Além disso, o risco dessa prática está relacionado à ausência de instrução e informação dos usuários sobre os perigos do uso de medicamentos por conta própria, o que leva ao uso desenfreado de fármacos Zution et al. (2017), gerando assim, problemas a saúde, como efeitos indesejáveis, interações medicamentosas, mascaramento de doenças, alergia, intoxicações e no caso de antibióticos pode ocasionar a resistência bacteriana (WHO, 2000)

Uns dos medicamentos observados na automedicação são os antibióticos, utilizados para matar bactérias ou impedir o seu crescimento (BRASIL, 2004). O desenvolvimento de antibacterianos foi um dos passos essências no controle de infecções por bactérias, pois contribui com tratamento de doenças que antes tinham grande chance de levar a morte (SILVEIRA et al., 2006). Contudo, recentemente a ação dos antibióticos está ameaçada pela resistência bacteriana (ZIMERMAN et al., 2010).

Os antibióticos podem ser encontrados em farmácias ou drogarias, mas segundo a resolução RDC 44, de 26 de outubro de 2010, da Agência Nacional de Vigilância Sanitária (ANVISA) não podem ser vendidos sem apresentação de receita médica (ZUTION et al., 2017). No entanto, em muitos lugares do Brasil é possível conseguilos sem apresentação de prescrição médica (SAMPAIO et al., 2018).

Por conta disso, o uso indevido de antibióticos tem levado ao surgimento de bactérias super-resistentes, isso ocorre quando esses microrganismos ficam expostos frequentemente aos antibióticos Who, 2018 ocasionando mutação, adaptação ou transferência gênica, que geram variações nos genes dando vantagens as bactérias mais aptas (MOTA et al., 2005).

Isso tem gerado preocupação, uma vez que 700.000 pessoas morrem a cada ano no mundo todo, como resultado de doenças resistentes a fármacos. Sem ações urgentes, até 2050 as superbactérias podem provocar a morte de aproximadamente 10 milhões de pessoas por ano, no pior cenário possível (IACG, 2019) 
Diante disso, observa-se a necessidade de difundir informações sobre os riscos provenientes da automedicação com antibióticos, além de sugerir boas práticas de educação em saúde bem como o uso racional de medicamentos, sobretudo os antibacterianos. Dessa forma, o objetivo desta pesquisa foi verificar a ocorrência da automedicação com antibióticos no município de Soure-Pará.

\section{METODOLOGIA}

Este estudo foi realizado no município de Soure-PA, no período de janeiro a março de 2019, com 120 moradores, sendo 60 mulheres e 60 homens, distribuídos entre a zona rural e urbana.

Foi utilizado como instrumento para coleta de dados questionários contendo 10 perguntas que abordavam questões sobre: sexo, idade, conhecimento sobre automedicação, utilização de antibiótico sem receita médica, motivo de usá-los, o nome do antibiótico usado, local de aquisição e conhecimento dos riscos de utilizá-los por conta própria.

O questionário foi aplicado em todos os bairros da cidade, totalizando doze, sendo cinco da área rural (Tucumanduba, Pesqueiro, Pedral, Céu e Caju- Una) e sete bairros da área urbana (Centro, Matinha, São Pedro, Macaxeira, Umirizal, Pacoval e Bairro Novo). Em cada bairro, foram selecionadas de forma aleatória, 10 casas sendo entrevistada uma pessoa por residência.

Os dados obtidos através dos questionários foram analisados em Programa Excel (versão 2010) e demonstrados em formas de gráficos e tabelas, expressos em números e porcentagens.

\section{RESULTADOS E DISCUSSÃO}

Foram aplicados 120 questionários, deste total 69 (57,5\%) das pessoas utilizavam antibiótico por conta própria e 51 (42,5\%) não faziam uso desse medicamento sem prescrição médica. 
Gráfico 1. Dados referentes ao uso de antibiótico por conta própria entre a população avaliada, Soure, 2019

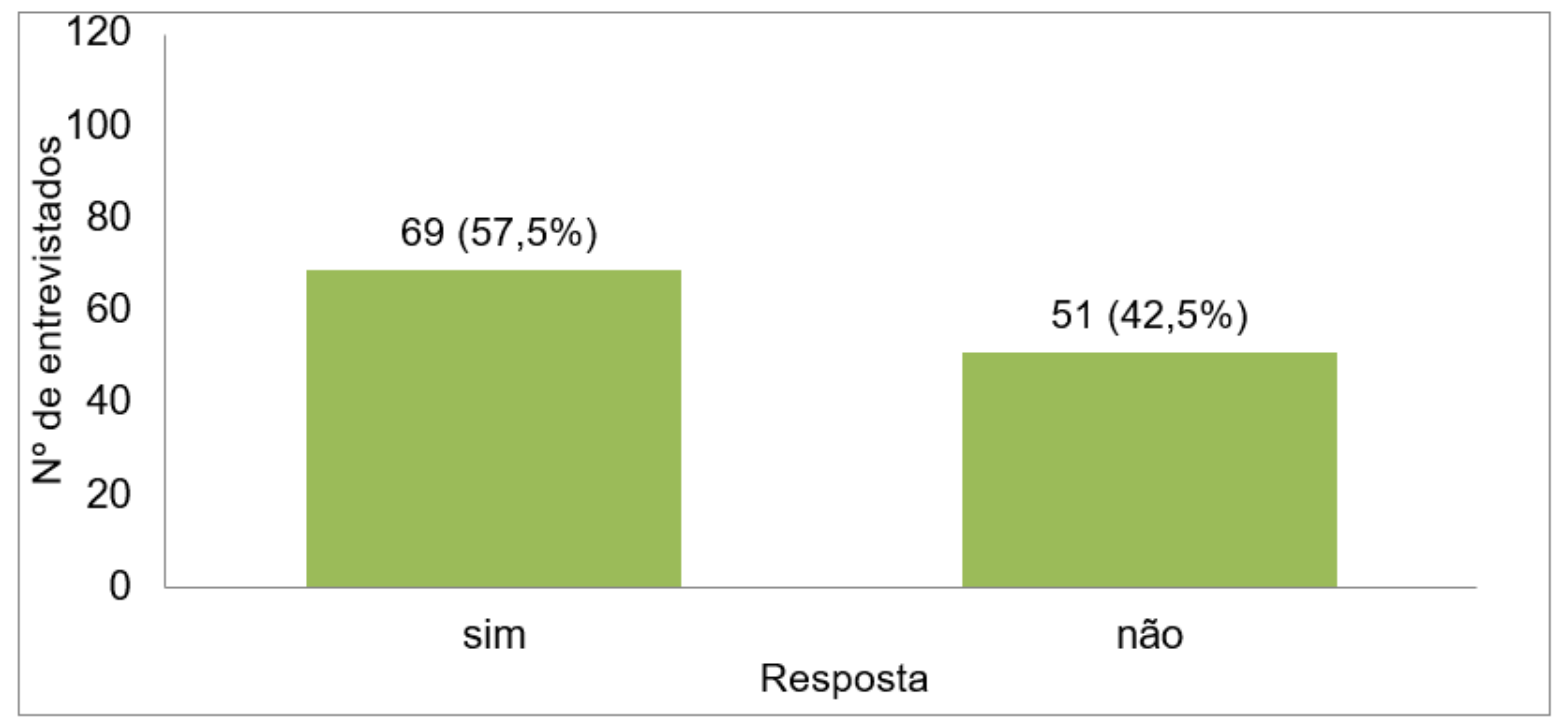

Fonte: Dados da pesquisa

Levando em consideração o público de 57,5\% que consome o antibiótico por conta própria, chegou-se à conclusão que este consumo se dá pela facilidade da população do município de Soure, adquirir esse fármaco sem receita médica, uma vez que nas farmácias local os atendentes não exigem receituário médico no ato da compra.

Os dados obtidos por este estudo, são similares ao encontrado por Arrais et al., (2016) que afirma que automedicação é um hábito recorrente e referem em seu estudo a incidência de $65,5 \%$ de quem consome medicamento sem receita médica.

No trabalho de Fonseca et al., (2018) foram encontrados resultados semelhantes em que o mesmo observou que no período de 15 dias dentre a população avaliada uma grande quantidade de pessoas se automedicou.

Além disso, o Conselho Nacional de Saúde, através de especialistas, atribui a alta incidência de remédios, às dificuldades que as pessoas tem no acesso aos serviços de saúde, e aos medicamentos serem vistos como mercadoria que pode ser adquirida e consumida sem a orientação devida (CNS, 2005). Todos esses fatores podem explicar o hábito das pessoas em se automedicar. 
Das 60 pessoas que se automedicavam no município de Soure, (86\%) informaram adquirir esse tipo de medicamento em farmácias sem apresentação de receita médica, pois há falta de controle na venda de antibióticos, já que em todas as farmácias de Soure não é exigido receita médica e pode-se adquirir facilmente, já que não há fiscalização por parte das agências reguladoras para punir essas atitudes, colaborando assim para o aumento da automedicação.

Conforme a resolução RDC 44, de 26 de outubro de 2010, da Agência Nacional de Vigilância Sanitária (ANVISA) não podem ser vendidos sem apresentação de receita médica.

Por conta disso, Damasceno et al., (2007) diz que é necessário melhor vigilância na venda de medicamentos, como os antibiótico.

De acordo com o questionário, foi observado o predomínio de consumo de antibióticos pelo sexo feminino (33\%) em relação ao sexo masculino (24\%).

Gráfico 2. Comparação da automedicação com antibióticos entre homens e mulheres janeiro/março de 2019.

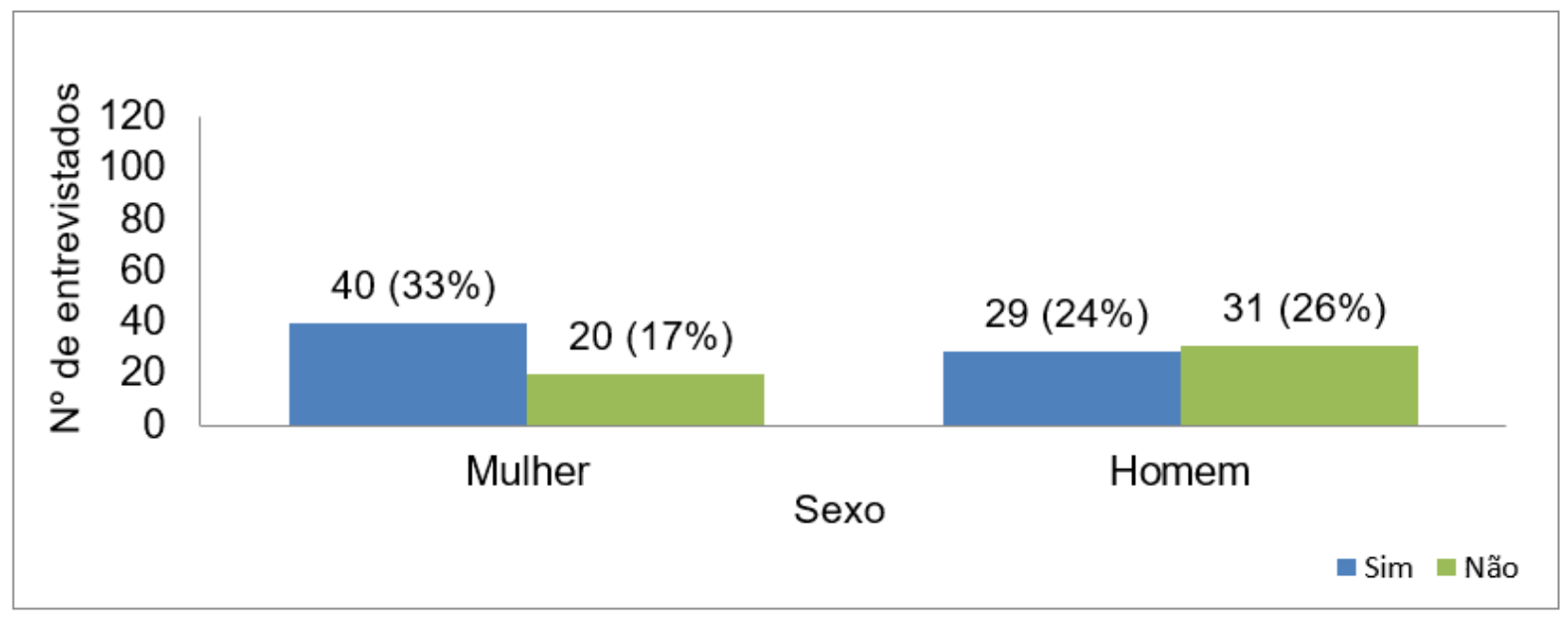

Fonte: Dados da pesquisa

O estudo de Arrais et al., (2005) descreveu que o uso mais frequente de automedicação entre as mulheres, e remete ao fato de que as mulheres cuidam mais de si mesma e da saúde da família. 
De fato, verifica-se que as mulheres são o público com maior incidência de uso de antibióticos. O que se pode atribuir a essa categoria feminina, é a facilidade que as mesma tem de buscarem mais os serviços de saúde, pela sua condição de terem maior preocupação com a saúde de seus familiares e pupilos e terem mais experiência em onde e como adquirir esses medicamentos e como usar, mesmo sem prescrição.

Em relação às zonas que foram entrevistadas, 70 pessoas eram moradores da área urbana e 50 pertenciam à área rural. Constatou-se que das 50 pessoas da zona rural, em torno de $(60 \%)$ consomem mais antibióticos sem orientação médica.

Tabela 1. Comparação da automedicação entre zona urbana e rural janeiro/março de 2019

\begin{tabular}{|c|c|c|c|}
\hline \multirow[t]{2}{*}{ Variável } & \multicolumn{2}{|c|}{ Automedicação } & \multirow[t]{2}{*}{ Total } \\
\hline & $\operatorname{Sim}(\%)$ & Não (\%) & \\
\hline Zona urbana & 39 (56\%) & 31 (44\%) & 70 \\
\hline Zona rural & 30 (60\%) & 20 (40\%) & 50 \\
\hline
\end{tabular}

Fonte: Dados da pesquisa

O maior consumo de antibióticos pela zona rural, pode ser explicado pelas falhas nas políticas públicas de saúde que cheguem até essas populações distantes e pela falta de acesso aos serviços de saúde nessas localidades, já que existe apenas um posto de saúde em cada comunidade rural para atender toda população e 0 atendimento médico, ocorre apenas uma vez por semana. Aliado a isso, às condições de acessibilidade geográfica e a ausência de farmácia na zona rural acaba levando as pessoas montarem suas "farmacinhas caseira" e estocarem medicamentos em casa, o que aumenta a automedicação nesta zona.

Para Naves et al., (2003) a dificuldade de acesso aos serviços saúde contribui na prática da automedicação. 
O antibiótico mais usado pela população do estudo foi a amoxilina correspondendo a $30 \%$.

Tabela 2. Antibióticos mais utilizados na prática da automedicação em Soure-PA janeiro/março de 2019

\begin{tabular}{|l|l|l|}
\hline Variável & N & $\%$ \\
\hline Antibióticos & & \\
\hline Amoxilina & 21 & 30 \\
\hline Sulfametoxazol & 12 & 17 \\
\hline Ampicilina & 11 & 16 \\
\hline Penicilina & 16 & 6 \\
\hline Azitromicina & 1 & 1 \\
\hline Tetraciclina & 1 & 1 \\
\hline Cefalexina & 1 & 1 \\
\hline Não lembro & 18 & 26 \\
\hline
\end{tabular}

Fonte: Dados da pesquisa

Esses dados podem ser explicados, pelo fato da amoxilina ser um antibacteriano bem receitado pelos médicos que trabalham em Soure, o que acaba tornando-se bastante conhecido pela população. Logo, acaba sendo usado outras vezes pelas mesmas pessoas devido já terem usado antes. Também é o mais indicado pelos atendentes de farmácias para as pessoas que procuram um antibiótico imediato.

Corroborando com o estudo de Mitre et al., (2017) onde a amoxilina foi o antimicrobiano mais prescrito pelos médicos.

Segundo Conceição et al., (2012) esse fármaco corresponde a uma grande frequência de utilização, pois o autor relata que essa classe de medicamentos é uma das mais usadas e receitadas, pois trata-se de um antibacteriano de largo espectro e baixa toxicidade, constituindo tratamento de primeira escolha para vários quadros infecciosos. Além disso, a grande experiência de uso clínico desse fármaco confere 
maior segurança ao prescrevê-lo (CNS, 2005). Por outro lado, o grande uso pode colaborar no agravamento de doenças e aumento da resistência bacteriana (RAMB, 2001).

O motivo mais mencionado para justificar a automedicação foi o alivio imediato de algum sintoma (57\%) (Tabela 3), já que esta prática proporciona tratamento momentâneo da dor e sofrimento, porém para Souza et al., (2011) pode não resolver adequadamente o problema e acrescenta risco de agravamento, o que pode retardar a comprovação do diagnóstico e o tratamento correto, sendo necessária procurar um médico antes de qualquer iniciativa medicamentosa (BAGGIO \& FORMAGGIO, 2007).

Tabela 3. Motivos que levaram a automedicação com antibióticos entre a população avaliada, Soure, 2019.

\begin{tabular}{|l|l|l|}
\hline Motivo da automedicação & $\mathrm{N}$ & $\%$ \\
\hline Alívio imediato de algum sintoma & 39 & 57 \\
\hline Não gosto de ir ao médico & 15 & 22 \\
\hline $\begin{array}{l}\text { Dificuldade de conseguir uma consulta } \\
\text { médica }\end{array}$ & 15 & 22 \\
\hline Fonte: Dados da pesquisa & & \\
\hline
\end{tabular}

Em relação aos riscos da automedicação $30 \%$ das pessoas não sabem os perigos causado por essa atitude, o que pode ser explicado pela falta de informação e conhecimento acerca dessa temática, pois em Soure as pessoas não tem um nível de conhecimento sobre esse assunto, uma vez que não existe uma política de educação cidadã em saúde pública atuante, de capacitação para os Agentes Comunitários de Saúde (ACS) que estão no dia a dia de forma mais próxima com as famílias para orienta-las quanto aos riscos oriundos da automedicação.

Diante disso, foi informado a população avaliada sobre os riscos provenientes da automedicação e orientado as pessoas a sempre procurarem um médico diante de qualquer problema de saúde. 
Para Mussolin, (2004) a educação em saúde é fundamental para diminuir os riscos e agravos decorrentes da automedicação.

\section{CONSIDERAÇÕES FINAIS}

Após a análise dos dados recorrente a prática da automedicação com antibióticos em Soure, foi observada que mais da metade da população utiliza esse medicamento de forma indevida, havendo a possibilidade de existir bactérias resistentes os antibacterianos no município.

Aliado a isso, a maioria das pessoas desconhecem os riscos oriundos desse hábito, sendo assim foi informado a população sobre os perigos da automedicação. Ademais, a automedicação foi mais frequente em moradores da zona rural, que é a área mais pobre do município e as dificuldades geográficas de se deslocar a procura de serviços de saúde na zona urbana, leva a essa parte da população a estocar aquilo que necessitam para situações que consideram imediatas.

Atribui-se ainda esse maior índice de automedicação na zona rural a falta de informações e consequentemente não possuírem um nível de conhecimento satisfatório sobre essa problemática.

O gênero feminino foi o que mais consumiu antibiótico por conta própria e o antibiótico amoxilina foi o mais relatado na pesquisa, além do motivo de apresentar aos usuários alivio imediato de algum sintoma.

Esse quadro se configura como um problema de saúde pública e risco para a população, tornando-se necessário o incentivo de práticas de educação em saúde que sensibilizem os indivíduos acerca dos danos provenientes da automedicação a fim de minimizar este hábito e contribuir com a melhoria da qualidade de vida dessas pessoas. 


\section{REFERÊNCIAS}

AQUINO, Daniela Silva de. Por que o uso racional de medicamentos deve ser uma prioridade?. Ciênc. saúde coletiva, Rio de Janeiro , v. 13, supl. p. 733736, Apr. 2008

ARRAIS PSD, FERNANDES MEP, DA SILVA DAL PIZZOL T, RAMOS LR, MENGUE SS, LUIZA VL, ET AL. Prevalência da automedicação no Brasil e fatores associados. Rev. Saúde Pública. 2016;50(supl 2):13s.

ARRAIS, Paulo Sérgio Dourado et al . Prevalência e fatores determinantes do consumo de medicamentos no Município de Fortaleza, Ceará, Brasil. Cad. Saúde Pública, Rio de Janeiro, v. 21, n. 6, p. 1737-1746, Dec. 2005.

AUTOMEDICAÇÃO. Rev. Assoc. Med. Bras., São Paulo , v. 47, n. 4, p. 269270, Dec. 2001.

BAGGIO MA, Formaggio FM. Profissional de enfermagem: compreendendo o autocuidado. Revista Gaúcha de Enfermagem 2007;28(2):233-41.

BORTOLON, Paula Chagas et al . Análise do perfil de automedicação em mulheres idosas brasileiras. Ciênc. saúde coletiva, Rio de Janeiro, v. 13, n. 4, p. 1219-1226, ago. 2008.

BRASIL. Ministério da Saúde. Glossário do Ministério da Saúde: projeto de terminologia em saúde / Ministério da Saúde - Brasília: Ministério da Saúde, 2004.

BRASIL. Política Nacional de Medicamentos. Brasília: Ministério da Saúde, p. 34, 2011.

CARVALHO, Marcelo Felga de et al . Utilization of medicines by the Brazilian population, 2003. Cad. Saúde Pública, Rio de Janeiro, v. 21, supl. 1, p. S100S108, 2005. 
CONCEIÇÃO, S \& MORAIS, D. C. M. Automedicação com antibióticos em estabelecimento farmacêutico do município de Mogi Mirim, SP, Brasil. Rev. Foco: Caderno de Estudo e Pesquisa. São Paulo, 2012.

CONSUMO DE MEDICAMENTOS: UM AUTOCUIDADO PERIGOSO. Conselho Nacional de Saúde 2005.2 Disponível em: http://www.conselho.saude.gov.br/ultimas_noticias/2005/medicamentos.htm. Acesso em: jul. 2019.

CONSUMO DE MEDICAMENTOS: UM AUTOCUIDADO PERIGOSO. Conselho Nacional de Saúde. 2005.2 Disponível em: http://www.conselho.saude.gov.br/ultimas_noticias/2005/medicamentos.htm. Acesso em: jul. 2019.

DAMASCENO, D. D; TERRA, F. S; ZANETTI, H. H. V.; D'ANDRÉA, E. D.; SILVA, H. L. R. \& LEITE, J. A. Automedicação entre graduandos de enfermagem, farmácia e odontologia da Universidade Federal de Alfenas. Revista Mineira de Enfermagem, 11. Minas Gerais, 2007.

INTERAGENCY COORDINATION GROUP ON ANTIMICROBIAL RESISTENCE IACG. Não há tempo a perder: acautelar o futuro contra infecções resistentes aos medicamentos. 2019. Disponível em: https://www.who.int/antimicrobialresistance/interagency-coordination-group/final-report/en/. Acesso em: mar. 2019.

MATOS, Januária Fonseca et al . Prevalência, perfil e fatores associados à automedicação em adolescentes e servidores de uma escola pública profissionalizante. Cad. saúde colet., Rio de Janeiro , v. 26, n. 1, p. 7683, Mar. 2018.

MITRE, G. S.; SILVA, S. A. B.; SILVA, G. A. B.; REZENDE, M. M. P. \& SOUSA JR, R. Perfil de prescrição de antimicrobianos nas unidades básicas de saúde conveniadas com a universidade de Itaúna/MG. Revista Médica de Minas Gerais, 27. Minas Gerais, 2017. 
MOTA, R. A.; SILVA, K. P. C.; FREITAS, M. F. L.; PORTO, W. J. N. \& SILVA, L. B. G. Utilização indiscriminada de antimicrobianos e sua contribuição a multirresitência bacteriana. Brazilian Journal of Veterinary Research and Animal Science, 42. Recife, 2005.

MUSSOLIN NM. A automedicação: um estudo entre universitários de enfermagem e de relações públicas [dissertação]. São Paulo (SP): Secretaria da Saúde. Coordenação dos Institutos de Pesquisa. Programa de Pós-Graduação em Ciências; 2004.

NAVES, Janeth de Oliveira Silva et al . Automedicação: uma abordagem qualitativa de suas motivações. Ciênc. saúde coletiva, Rio de Janeiro, v. 15, supl. 1, p. 1751 1762, June, 2010.

SAMPAIO, Pamella da Silva; SANCHO, Leyla Gomes; LAGO, Regina Ferro do. Implementação da nova regulamentação para prescrição e dispensação de antimicrobianos: possibilidades e desafios. Cad. saúde colet., Rio de Janeiro, v. 26, n. 1, p. 15-22, Mar. 2018.

SILVEIRA, Gustavo Pozza et al . Estratégias utilizadas no combate a resistência bacteriana. Quím. Nova, São Paulo, v. 29, n. 4, p. 844-855, July 2006.

SOUZA LAF, Silva CD, Ferraz GC, Faleiros Sousa FAE, Pereira LV. Prevalência e caracterização da prática de automedicação para alívio da dor entre estudantes universitários de enfermagem. Rev. Latino-Am. Enfermagem [Internet]. marabr 2011.

WORLD HEALTH ORGANIZATION. Guidelines for the Regulatory Assessment of Medicinal Products for use in Self-Medication. Geneva: World Health Organization, 2000.

WORLD HEALTH ORGANIZATION. World Antibiotic Awarenese Week. 2018 Disponível em: https://www.who.int/campaigns/world-antibiotic-awarenessweek/world-antibiotic-awareness-week-2018. Acesso em: mar. 2019. 
ZIMERMAN, Ricardo Ariel Uso indiscriminado de antibióticos e resistência microbiana. ANVISA, 1. Brasília, 2010.

ZUTION, J. R.; SILVA, D. R. \& CARMO, R. G. Riscos da automedicação e o uso irracional de antibióticos. In: Congresso Nacional de Conhecimento/ Congresso Nacional dos Estudantes, 11. Porto Seguro, 2017. Anais do Congresso Nacional de Conhecimento/ Congresso Nacional dos Estudantes. Bahia: Porto Seguro, 2017.

Enviado: Junho, 2020.

Aprovado: Junho, 2020. 